\title{
The Effect of Driving Intensity and Incomplete Charging on the Fuel Economy of a Hymotion Prius PHEV
}

\author{
R. Carlson \\ J. Francfort \\ M. Shirk \\ J. Smart
}

October 2009

The Idaho National Laboratory is a U.S. Department of Energy National Laboratory Operated by Battelle Energy Alliance 
INL/EXT-09-16503

\title{
The Effect of Driving Intensity and Incomplete Charging on the Fuel Economy of a Hymotion Prius PHEV
}

\author{
R. Carlson \\ J. Francfort \\ M. Shirk \\ J. Smart
}

October 2009

\begin{abstract}
Idaho National Laboratory
Transportation Technology Department

Idaho Falls, Idaho 83415
\end{abstract}

Prepared for the

U.S. Department of Energy

Assistant Secretary for Energy Efficiency and Renewable Energy

Under DOE Idaho Operations Office

Contract DE-AC07-05ID14517 


\section{Disclaimers}

This document highlights work sponsored by agencies of the U.S. Government. Neither the U.S. Government nor any agency thereof, nor any of its employees, makes any warranty, express or implied, or assumes any legal liability or responsibility for the accuracy, completeness, or usefulness of any information, apparatus, product, or process disclosed, or represents that its use would not infringe privately owned rights. Reference herein to any specific commercial product, process, or service by trade name, trademark, manufacturer, or otherwise does not necessarily constitute or imply its endorsement, recommendation, or favoring by the U.S. Government or any agency thereof. The views and opinions of authors expressed herein do not necessarily state or reflect those of the U.S. Government or any agency thereof. 


\begin{abstract}
On-road testing was conducted on a Hymotion Prius plug-in hybrid electric vehicle (PHEV) at the Electric Transportation Engineering Corporation in Phoenix, Arizona. The tests were comprised of on-road urban and highway driving during charge-depleting and charge-sustaining operation. Determining real-world effectiveness of PHEVs at reducing petroleum consumption in real-world driving was the main focus of the study. Throughout testing, several factors that affect fuel consumption of PHEVs were identified.

This report discusses two of these factors: driving intensity (i.e., driving aggressiveness) and battery charging completeness. These two factors are unrelated, yet both significantly impact the vehicle's fuel economy. Driving intensity was shown to decrease fuel economy by up to half. Charging completeness, which was affected by human factors and ambient temperature conditions, also showed to have great impact on fuel economy for the Hymotion Prius.

These tests were performed for the U.S. Department of Energy's Advanced Vehicle Testing Activity. The Advanced Vehicle Testing Activity, part of the U.S. Department of Energy's Vehicle Technology Program, is conducted by the Idaho National Laboratory and the Electric Transportation Engineering Corporation.
\end{abstract}




\section{CONTENTS}

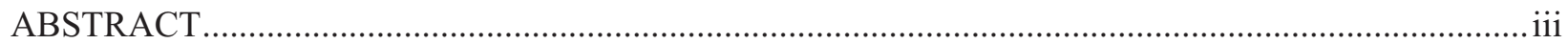

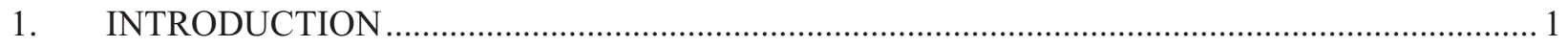

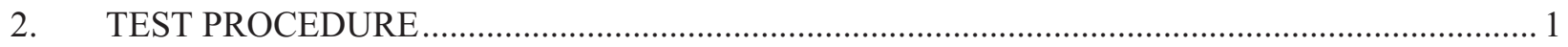

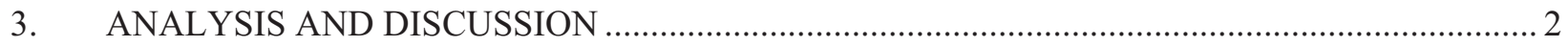

3.1 Effect of Driving Intensity on Fuel Consumption.................................................. 3

3.2 Importance of Complete Charging Events .............................................................. 6

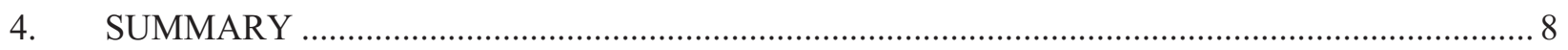

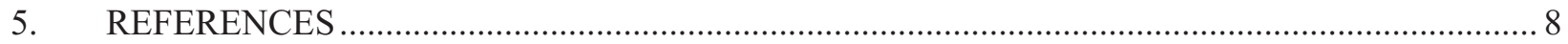

\section{FIGURES}

1. Fuel and electrical energy consumption of Hymotion Prius over 40-mile tests .............................2

2. Fuel and electrical energy consumption of tests with fully charged battery .................................. 3

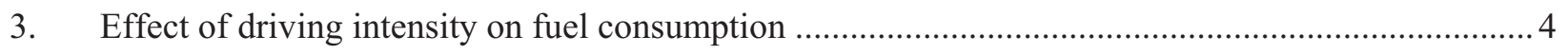

4. Effect of vehicle speed above $40 \mathrm{mph}$ on fuel consumption....................................................... 5

5. Relationship between vehicle speed above $40 \mathrm{mph}$ and driving intensity .................................... 5

6. High battery temperature can lead to incomplete charging events ............................................. 7

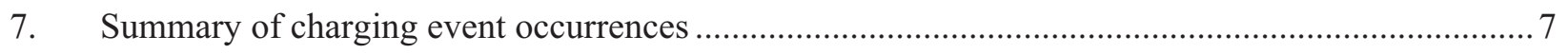

\section{TABLES}

1. The Advanced Vehicle Testing Activity's accelerated testing for plug-in hybrid electric vehicles .1

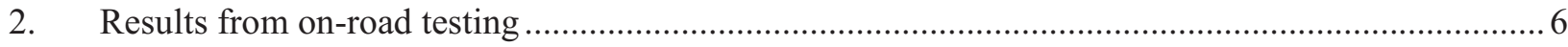




\section{The Effect of Driving Intensity and Incomplete Charging on the Fuel Economy of a Hymotion Prius PHEV}

\section{INTRODUCTION}

From late 2008 through early 2009, many tests were conducted on a Hymotion Prius plug-in hybrid electric vehicle (PHEV) conversion at the Electric Transportation Engineering Corporation in Phoenix, Arizona. The tests were comprised of urban and highway driving during charge-depleting and charge-sustaining operation. The main focus of the testing was to determine the effectiveness of PHEVs at reducing petroleum consumption in real-world driving (Iu and Smart). Throughout this testing, several factors that affect fuel consumption of PHEVs were identified. This report discusses two of these factors: driving intensity (i.e., driving aggressiveness) and battery charging completeness. These two factors are unrelated, yet both factors significantly impact the vehicle's fuel economy.

These tests were performed for the U.S. Department of Energy's Advanced Vehicle Testing Activity. The Advanced Vehicle Testing Activity, part of the U.S. Department of Energy's Vehicle Technology Program, is conducted by the Idaho National Laboratory and the Electric Transportation Engineering Corporation.

\section{TEST PROCEDURE}

PHEV accelerated testing was conducted on the Hymotion Prius and involved nine 600-mile-long testing sequences that consisted of combinations of urban and highway driving loops. Each urban and highway driving loop was 10 miles in length. These tests were repeated until 600 miles were accumulated. Table 1 shows the accelerated testing sequences. The three 40-mile test cycles are analyzed in this discussion. These test sequences are comprised of four urban, two urban/two highway, or four highway loops.

Table 1. The Advanced Vehicle Testing Activity's accelerated testing for plug-in hybrid electric vehicles.

\begin{tabular}{|c|c|c|c|c|c|c|c|}
\hline $\begin{array}{c}\text { Cycle } \\
(\mathbf{m i})\end{array}$ & $\begin{array}{c}\text { Urban } \\
(\mathbf{1 0} \mathbf{~ m i})\end{array}$ & $\begin{array}{c}\text { Highway } \\
(\mathbf{1 0} \mathbf{~ m i})\end{array}$ & $\begin{array}{c}\text { Charge } \\
\text { (hr) }\end{array}$ & $\begin{array}{c}\text { Reps } \\
\text { (N) }\end{array}$ & $\begin{array}{c}\text { Total } \\
(\mathbf{m i})\end{array}$ & $\begin{array}{c}\text { Reps } \\
(\mathbf{\%})\end{array}$ & $\begin{array}{c}\text { Miles } \\
(\mathbf{\%})\end{array}$ \\
\hline 10 & 1 & 0 & 4 & 60 & 600 & $37 \%$ & $11 \%$ \\
\hline 20 & 1 & 1 & 8 & 30 & 600 & $19 \%$ & $11 \%$ \\
\hline 40 & 4 & 0 & 12 & 15 & 600 & $9 \%$ & $11 \%$ \\
\hline 40 & 2 & 2 & 12 & 15 & 600 & $9 \%$ & $11 \%$ \\
\hline 40 & 0 & 4 & 12 & 15 & 600 & $9 \%$ & $11 \%$ \\
\hline 60 & 2 & 4 & 12 & 10 & 600 & $6 \%$ & $11 \%$ \\
\hline 80 & 2 & 6 & 12 & 8 & 640 & $5 \%$ & $12 \%$ \\
\hline 100 & 2 & 8 & 12 & 6 & 600 & $4 \%$ & $11 \%$ \\
\hline 200 & 2 & 18 & 12 & 3 & 600 & $2 \%$ & $11 \%$ \\
\hline Total & $\mathbf{2 , 3 4 0}$ & $\mathbf{3 , 1 0 0}$ & $\mathbf{1 , 3 4 4}$ & $\mathbf{1 6 2}$ & $\mathbf{5 , 4 4 0}$ & & \\
\hline Average & $\mathbf{4 3} \%$ & $\mathbf{5 7 \%}$ & $\mathbf{8 . 3}$ & $\mathbf{1 8}$ & & & \\
\hline
\end{tabular}


A real-world test procedure that is representative of expected typical driver behavior was followed. Driving included real-world driving events such as traffic lights, weather conditions, and traffic congestion. However, this real-world testing did not include accessory utilization (e.g., air conditioner or defroster) or the use of cruise control. Before testing, the vehicle was charged from a standard 110 Volt wall plug for the minimum number of hours as shown in Table 1 in preparation for the following test cycle. The odometer was manually recorded before and after each test was conducted. The AC electricity from the wall plug after each charge event also was recorded. The amount of gasoline consumed also was recorded manually when the vehicle was refueled at the conclusion of each 600-mile test cycle sequence. The vehicles were outfitted with a V2Green datalogger that measures and records several parameters at $1 \mathrm{~Hz}$, including fuel flow, battery current and voltage, and vehicle speed.

\section{ANALYSIS AND DISCUSSION}

Data from all 40-mile tests between November 2008 and July 2009, in which V2Green data was received, are shown in Figure 1. This figure shows fuel and electrical energy consumption. Urban tests are shown in red, urban/highway tests are shown in blue, and highway tests are shown in green. Overall, tests were conducted at the same speeds for the given driving loop; however, driving intensity (or driver aggressiveness) was distinctly changed between the two phases of testing. Driving aggressiveness is defined as the energy at the wheels required for propulsion and is typically reported in units of watt-hours per mile (Tate et al. and Carlson et al.). The greater the vehicle acceleration or the faster the overall vehicle speed, then the greater the driving intensity.

In the first phase of testing, driving aggressiveness was rather high due to quick accelerations and slightly higher vehicle speeds. The second phase of testing was conducted with less aggressive driving accomplished by smoother, slower accelerations. This resulted in higher driving intensity in the first phase of testing when compared to the second phase. Note that for tests resulting in similar electrical consumption, the fuel consumption is generally greater in the first phase. This is primarily due to increased driving intensity.

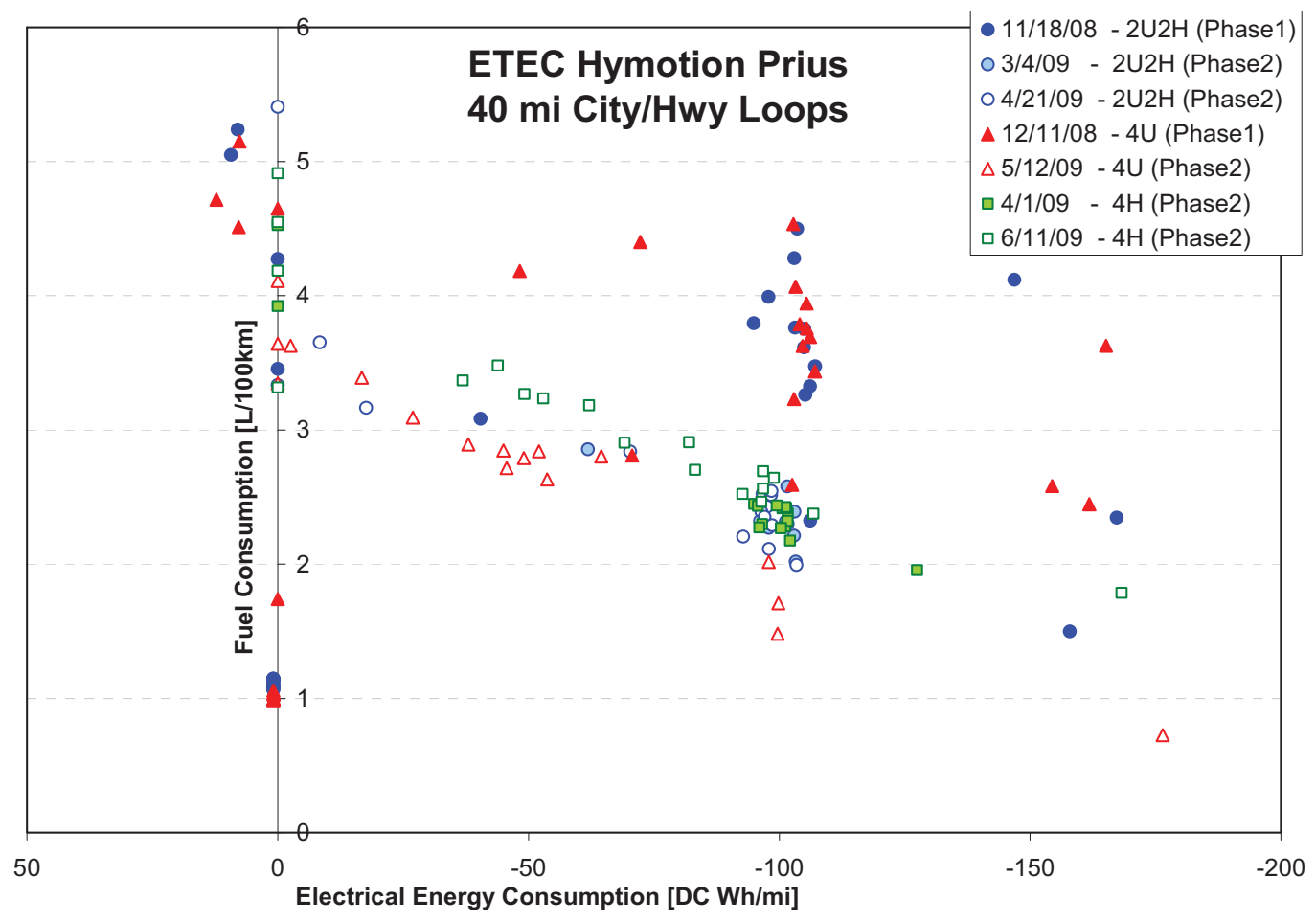

Figure 1. Fuel and electrical energy consumption of Hymotion Prius over 40-mile tests. 


\subsection{Effect of Driving Intensity on Fuel Consumption}

Several tests did not begin with a full battery state of charge. This was due to the AC voltage being interrupted before the pack was fully charged or because the charger stopped transferring power to the battery system, which was predominantly due to high temperatures. In an effort to isolate the effects of driving intensity, only the tests that started at a full state of charge are shown in Figure 2. Note the distinction between the first phase and second phase of testing now appears to be more predominant. Figure 2 shows the urban tests in Phase 1 with fuel consumption between 3.2 and $4.5 \mathrm{~L} / 100 \mathrm{~km}$ (74 and $52 \mathrm{mpg}$ ), whereas the urban tests in Phase 2 show fuel consumption between 1.5 and $2.7 \mathrm{~L} / 100 \mathrm{~km}(157$ and $87 \mathrm{mpg})$.

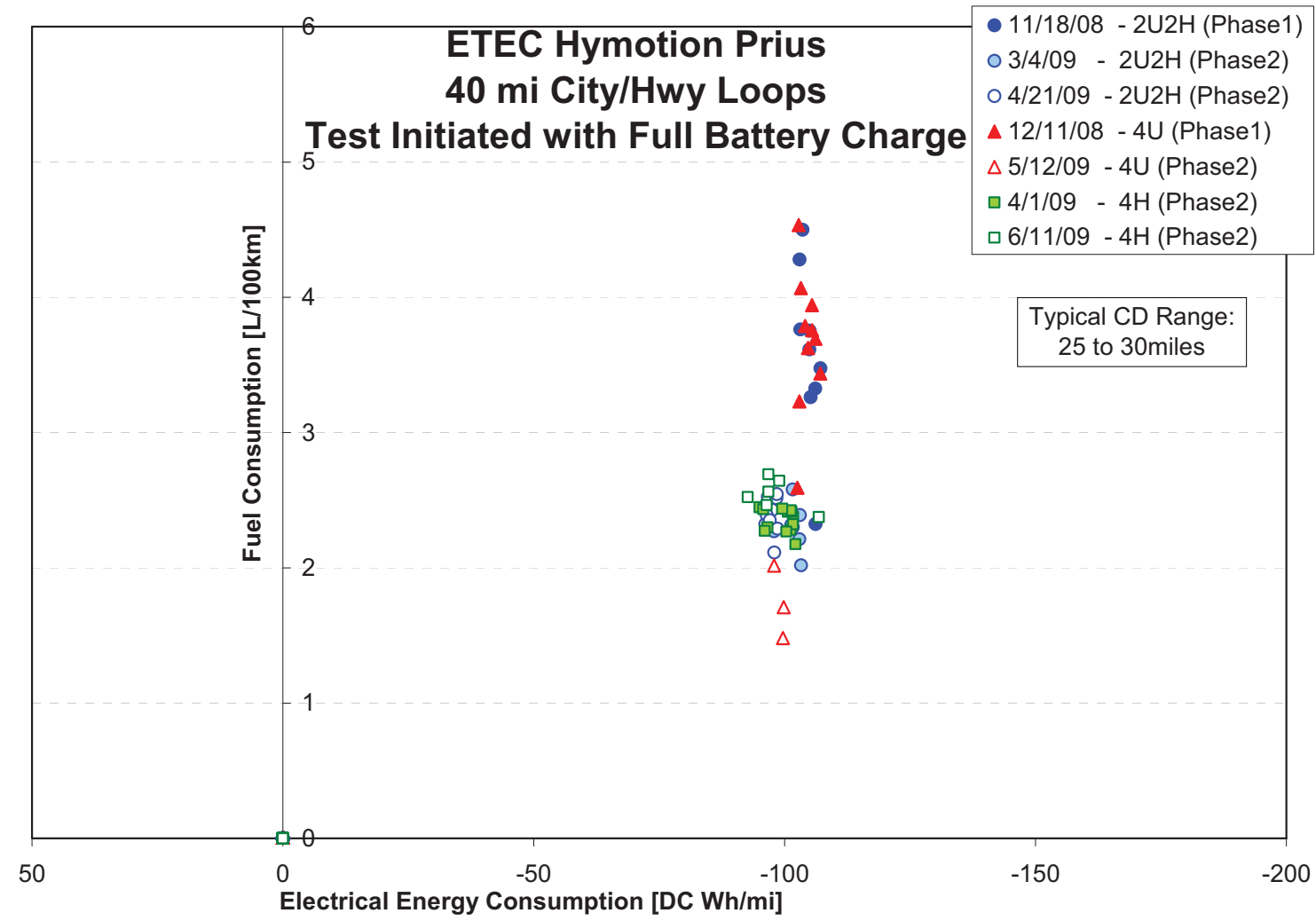

Figure 2. Fuel and electrical energy consumption of tests with fully charged battery.

Note that all results in Figure 2 show nearly the same electrical energy consumption (about $100 \mathrm{DC} \mathrm{Wh} / \mathrm{mi}$ ). The charge-depleting range of the Hymotion Prius is between 25 to 30 miles for the given test loops. Because all of the tests conducted were 40 miles, the Hymotion battery system was fully depleted by the end of each test. Also, the usable energy capacity of the Hymotion battery system is nearly constant (about $4 \mathrm{DC} \mathrm{kWh}$ ); therefore, electrical energy consumption for the 40-mile tests is nearly constant.

The main difference between the first and second phases of testing is driving intensity (aggressiveness). Driving intensity is the energy at the wheels used for propulsion. Recaptured energy through regenerative braking is not considered when calculating driving intensity. Figure 3 shows the impact on vehicle fuel consumption of increasing the driving intensity. As driving intensity increases, fuel consumption increases as a nearly linear relationship because the rate for battery depletion was nearly constant for all tests. 


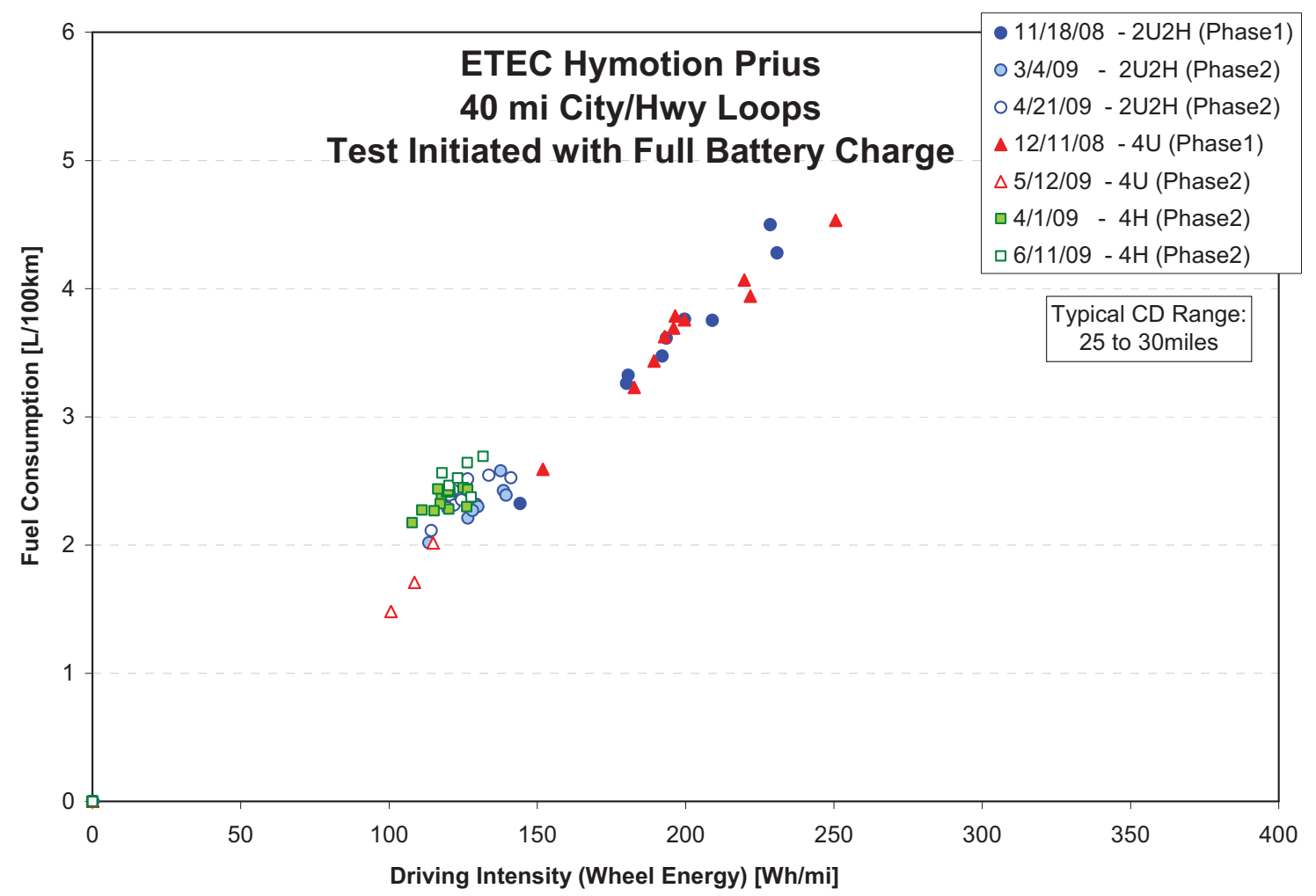

Figure 3. Effect of driving intensity on fuel consumption.

For all Prius vehicles, the engine crankshaft is spinning when the vehicle speed is above $40 \mathrm{mph}$ due to internal powertrain kinematic constraints; however, the engine is not necessarily consuming fuel while spinning (e.g., deceleration fuel cut-off while braking). Unexpectedly, a strong correlation does not exist in these tests between fuel consumption and driving above $40 \mathrm{mph}$ (see Figure 4). At considerably higher speeds, fuel consumption is directly impacted by vehicle speed. This is due to increasing aerodynamic losses at higher vehicle speeds not an engine on/off characteristic. Figure 4 shows fuel consumption with respect to the percent time above $40 \mathrm{mph}$. For a given style of driving loop (e.g., city or highway), a trend can be seen that shows increased fuel consumption with increased time above $40 \mathrm{mph}$, but this is mainly due to increased driving intensity. Examining only Phase 1 results shows the fuel consumption to average $3.6 \mathrm{~L} / 100 \mathrm{~km}$ regardless of the time above $40 \mathrm{mph}$. Likewise, with the Phase 2 results, fuel consumption averages $2.5 \mathrm{~L} / 100 \mathrm{~km}$, except for the urban only drive events, which averaged under $2.0 \mathrm{~L} / 100 \mathrm{~km}$. This shows that for moderate driving speeds, the engine on/off characteristic has only a secondary effect on fuel consumption.

Two factors that contribute to increased fuel consumption (i.e., vehicle speed above $40 \mathrm{mph}$ and driving intensity) have been examined. Figure 5 shows the trends of urban, urban highway mixed, and highway only driving for driving intensity compared to percent time above $40 \mathrm{mph}$. This plot is very similar to Figure 4, which shows that fuel consumption increase in these tests is predominately caused by driving intensity, not by significant time driving above $40 \mathrm{mph}$. 


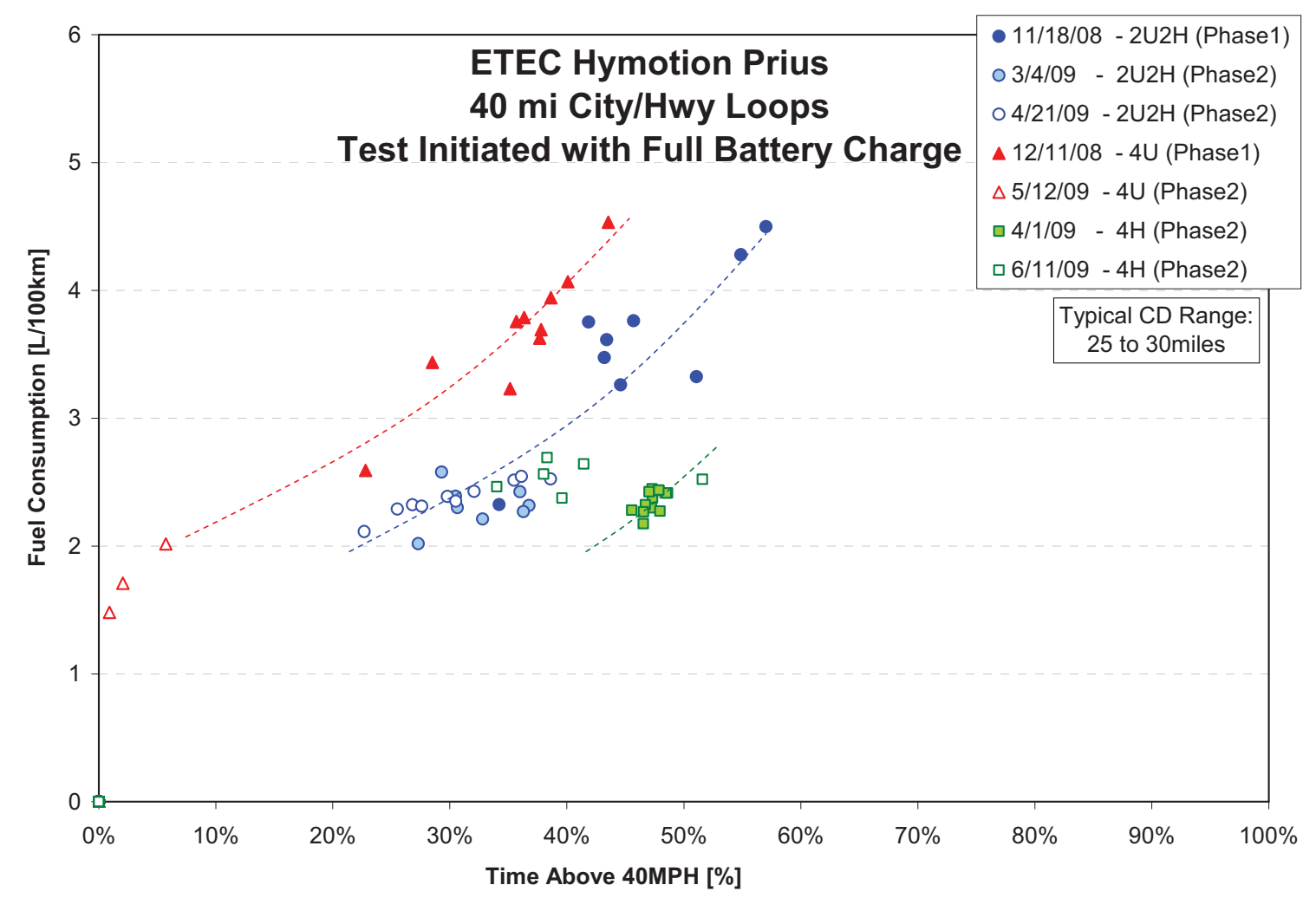

Figure 4. Effect of vehicle speed above $40 \mathrm{mph}$ on fuel consumption.

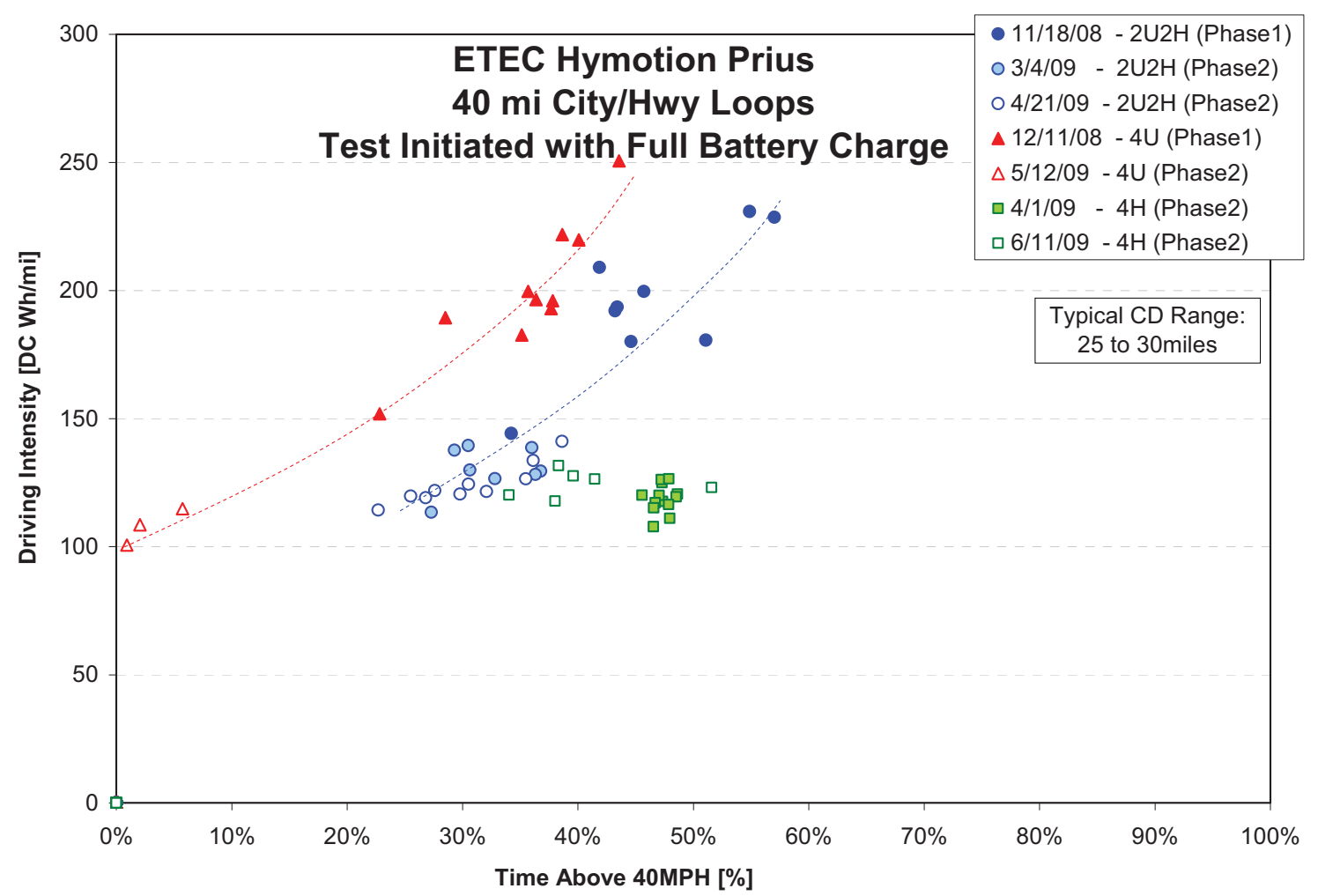

Figure 5. Relationship between vehicle speed above $40 \mathrm{mph}$ and driving intensity. 
When a 40 -mile test is initiated with an initial state of charge less than $100 \%$, fuel consumption is greater because less electrical energy is available. This results in the vehicle operating in charge-sustaining mode for more of the test and a lower fuel economy. To isolate fuel consumption comparison of the driving style between the two phases of tests, the overall fuel economy was recalculated using only tests that began with a full state of charge (the results are shown in Table 2).

Table 2. Results from on-road testing.

\begin{tabular}{|c|c|c|c|c|c|c|c|c|c|}
\hline \multirow[b]{2}{*}{$\begin{array}{l}\text { Date range } \\
\text { of tests }\end{array}$} & \multicolumn{4}{|c|}{ Production HyMotion Prius } & \multirow[b]{2}{*}{$\begin{array}{c}\text { Electricity } \\
\text { (kWh) }\end{array}$} & \multirow[b]{2}{*}{ Gasoline } & \multirow[b]{2}{*}{$\begin{array}{c}\text { MPG } \\
\text { Summary }\end{array}$} & \multicolumn{2}{|c|}{ Imcomplete Charging Events Removed } \\
\hline & $\begin{array}{c}\text { Cycle } \\
\text { (mi) }\end{array}$ & $\begin{array}{c}\text { Urban } \\
(10 \mathrm{mi})\end{array}$ & $\begin{array}{c}\text { Highway } \\
\text { (10 mi) }\end{array}$ & $\begin{array}{c}\text { Total } \\
\text { (mi) }\end{array}$ & & & & $\begin{array}{l}\text { ReCalculated } \\
\text { MPG }\end{array}$ & $\begin{array}{l}\text { ReCalculated } \\
\mathrm{Wh} / \mathrm{mi}\end{array}$ \\
\hline $12 / 11-1 / 13 / 09$ & 40 & 4 & 0 & 600 & 71.3 & 9.8 & 62.1 & 64.2 & 104.4 \\
\hline $5 / 12-6 / 5 / 09$ & 40 & 4 & 0 & 600 & 45.0 & 7.2 & 84.2 & 135.6 & 99.1 \\
\hline $11 / 18-12 / 10 / 08$ & 40 & 2 & 2 & 600 & 64.4 & 9.7 & 64.3 & 65.6 & 104.9 \\
\hline $3 / 3-3 / 25 / 09$ & 40 & 2 & 2 & 600 & 75.1 & 6.2 & 99.8 & 101.7 & 101.1 \\
\hline $4 / 21-5 / 11 / 09$ & 40 & 2 & 2 & 600 & 71.0 & 6.8 & 90.6 & 98.9 & 97.4 \\
\hline $3 / 31-4 / 20 / 09$ & 40 & 0 & 4 & 600 & 75.2 & 6.1 & 103.3 & 100.0 & 99.5 \\
\hline $6 / 8-6 / 30 / 09$ & 40 & 0 & 4 & 600 & 63.5 & 8.9 & 70.8 & 92.4 & 97.9 \\
\hline
\end{tabular}

Note that the change in driving style over urban driving only (shown in blue) shows a $2 \mathrm{X}$ change in fuel economy (64 mpg versus $136 \mathrm{mpg}$ ); however, they have very similar electrical energy consumption because the pack is fully depleted before the end of the test. Similar results are seen in the mixed urban and highway testing when comparing driving styles (shown in yellow).

For highway tests (shown in green), the driving style was not changed from April to June. The main difference between the April and June highway tests is the ambient temperature, which caused incomplete charging events. This is shown in Table 2 (103 mpg versus $71 \mathrm{mpg}$ ) in the green highlighted section. Disregarding the incomplete charge events, the highway fuel economy is more consistent (100 mpg versus $92 \mathrm{mpg}$ ). This small difference can mainly be attributed to differing driver intensity and other real-world factors.

\subsection{Importance of Complete Charging Events}

Several tests were initiated without a full battery state of charge. Some occurrences were due to insufficient time plugged in (i.e., short charge), while other occurrences were due to the charger operation stopping before the battery was completely charged (i.e., incomplete charge).

Short-charge events occurred when the wall plug power source was disconnected from the vehicle before the battery was fully charged. This was due to either an operator unplugging the vehicle or the power supply being interrupted (e.g., tripped circuit breaker) before the charging event was completed. Incomplete charging events were due to charger operation stopping before reaching a full battery state of charge even though $\mathrm{AC}$ wall plug voltage was still present. Through this testing, there were a total of nine short-charge events. Six of these events occurred due to a problematic ground fault circuit interrupter, which would disconnect power from the vehicle's charger well before the battery was fully recharged. This ground fault circuit interrupter unit was subsequently replaced. The other three short-charge events were due to driver error of unplugging the vehicle before the recharge event completed. The occurrences of incomplete charging are shown to correlate to high ambient temperature while charging. Figure 6 shows battery inlet air temperature and its effect on complete charging. Above battery inlet air temperatures of $138^{\circ} \mathrm{F}$, incomplete charging events occur because the battery control system safely prevents overheating of the battery by terminating charging. Continuing to charge would continue to increase battery cell temperature, which may create an unsafe condition. 


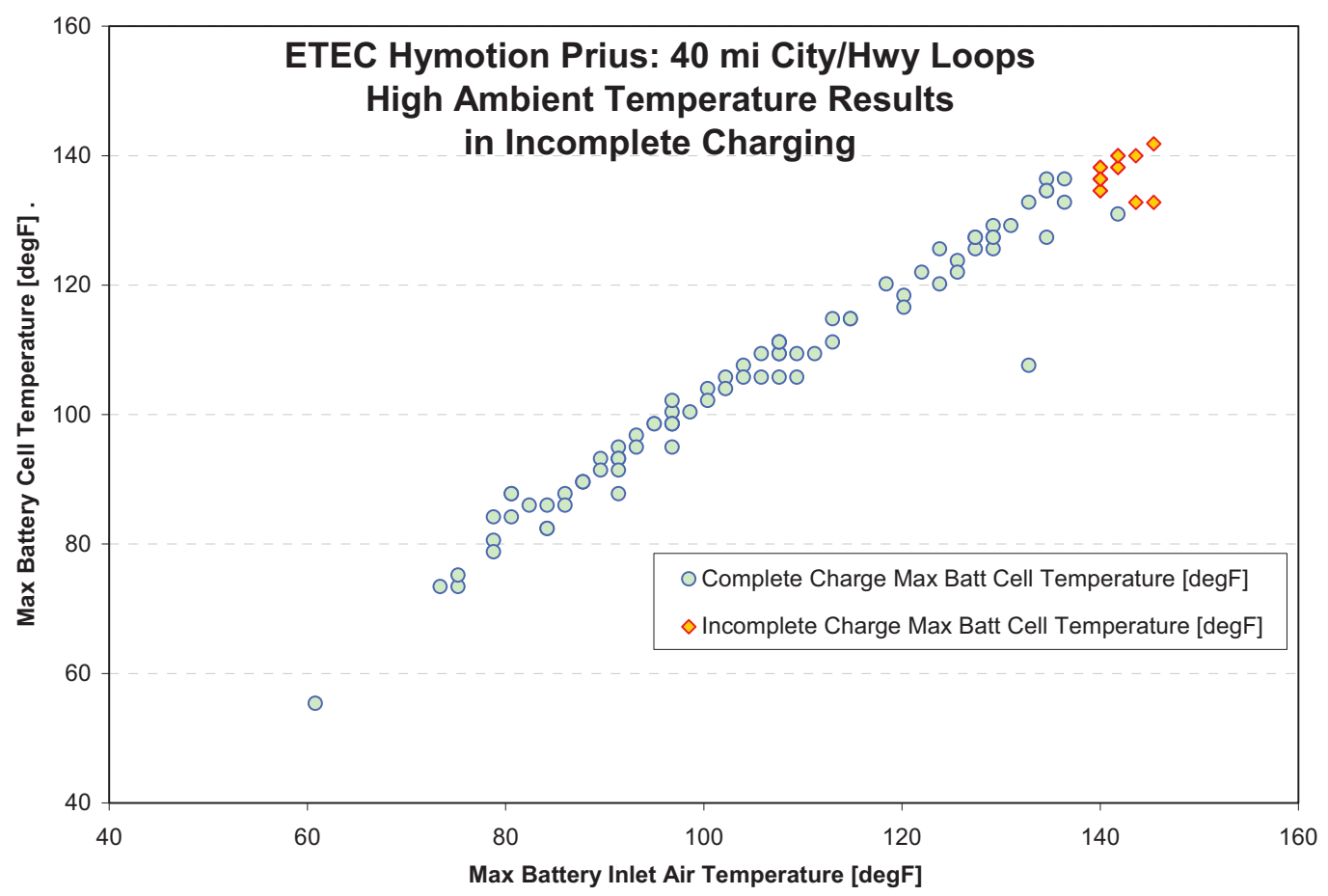

Figure 6. High battery temperature can lead to incomplete charging events.

Figure 7 shows the number of completed, short charge, and incomplete charging events. As shown in Table 2, the incomplete charging events and the short-charge events together have a significant impact on the vehicle's fuel economy. By operating the vehicle without beginning at a full battery state of charge, the potential petroleum displacement is directly impacted because less electrical energy is available for propulsion; therefore, more petroleum fuel is required.

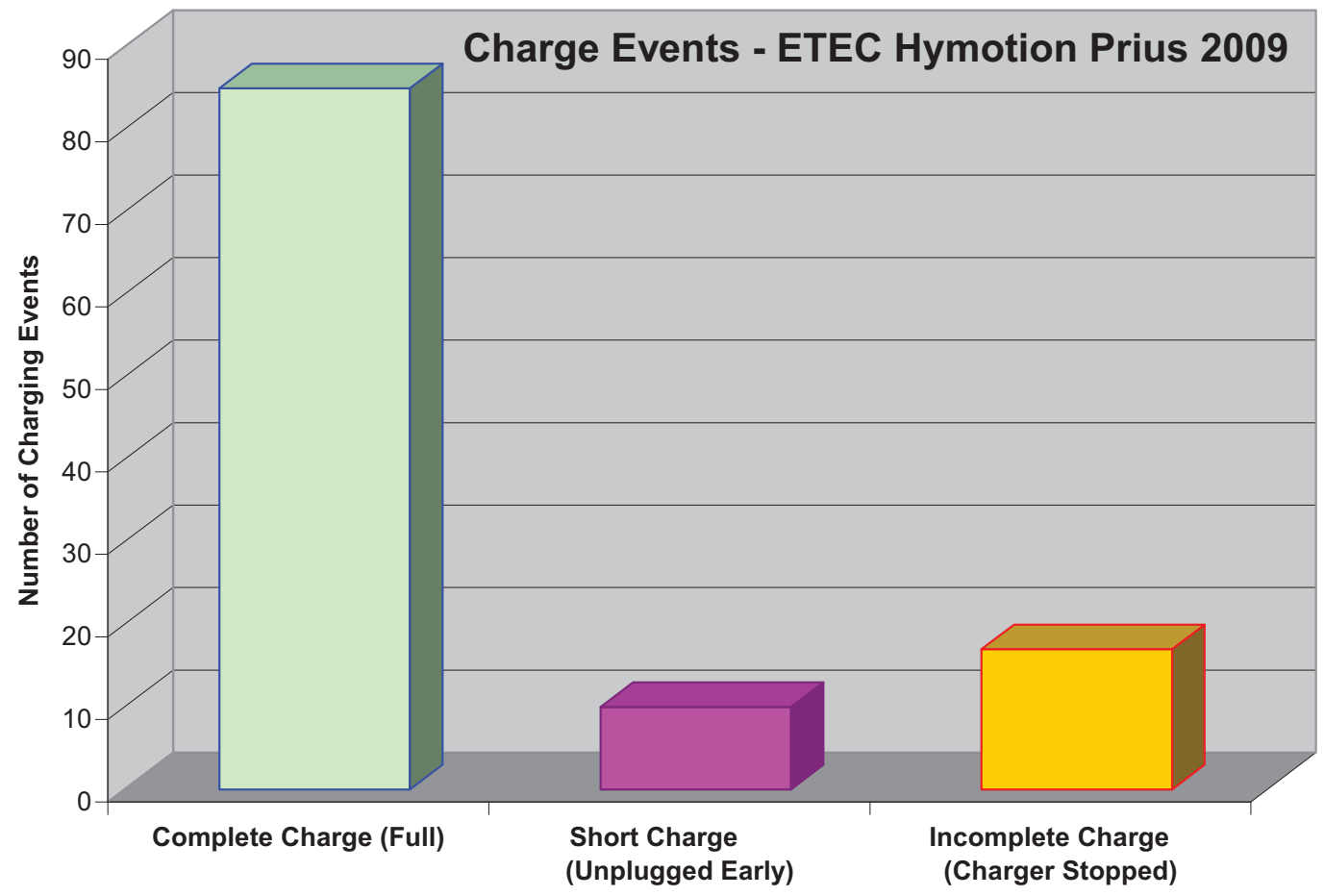

Figure 7. Summary of charging event occurrences. 


\section{SUMMARY}

These 40-mile tests have shown that for one PHEV, two independent factors (i.e., driving intensity and charging energy) from real-world driving have significant impact on the vehicle's fuel consumption. Driving intensity impacted fuel consumption by a factor of two, and incomplete charging (along with short-charge events) also showed a significant fuel consumption increase, depending on the amount of charge that was received before the charge event was terminated. Both of these factors are quite variable, with considerable influence from the vehicle operator, except for incomplete charging due to high temperatures. This analysis has reinforced the fact that the vehicle operator is a critical link to enabling the PHEV to achieve its high fuel economy potential.

\section{REFERENCES}

Carlson, R., et. al., Drive Cycle Fuel Consumption Variability of Plug-In Hybrid Electric Vehicles due to Aggressive Driving, SAE 2009-01-1335.

Iu, H. and J. Smart, Report on the Field Performance of the A123Systems' Hymotion Plug-In Conversion Module for the Toyota Prius, SAE 2009-01-1331.

Tate, E., et. al., The Electrification of the Automobile: From Conventional Hybrid, to Plug-in Hybrids, to Extended-Range Electric Vehicles, SAE 2008-01-0458. 